\title{
Variations
}

Variations

Revue internationale de théorie critique

18 | 2013

"La poésie est une arme chargée de futur »

\section{Prise de plume}

Hamidou Valian

\section{OpenEdition}

Journals

Édition électronique

URL : http://journals.openedition.org/variations/649

DOI : 10.4000/variations. 649

ISSN : 1968-3960

\section{Éditeur}

Les amis de Variations

\section{Référence électronique}

Hamidou Valian, «Prise de plume », Variations [En ligne], 18 | 2013, mis en ligne le 15 mai 2013, consulté le 26 avril 2019. URL : http://journals.openedition.org/variations/649 ; DOI : 10.4000/ variations. 649

Ce document a été généré automatiquement le 26 avril 2019

Les ami•e•s de Variations 


\section{Prise de plume}

\section{Hamidou Valian}

Sans une plume que serait nos vies

De savoir perdu le rempart de nos furies

Pourquoi sommes-nous si l'on ne nous permet que de suivre

Alors que nous aimons la liberté au point d'en être ivre

Ce monde ne nous sied-il

Ou est-ce plutôt nous qui lui sommes hostiles

Où trouver refuge loin des moules qui standardisent

Nous que leurs codes et règles de politesse tamisent

Et qui venons sur leur feu jeter de l'encre

Pour faire renaître de l'amour des cœurs cancres?

Sans un pinceau que seraient nos tableaux

De savoir ce ciel ouvert un vaste cachot

Pourquoi peintre être si à la mime l'on nous confine

Avec tout ce remue-méninge que reflètent nos babines

Cette terre ne nous sied-elle

Ou est-ce plutôt nous qui lui faisons querelle

Comment faire de fines lignes avec nos plumes tordues

Nous que la tâche a écorchés sans avoir promus

Promis à l'anonymat par inadéquation de format

On versifie à contre-sens des mécènes et leurs médias.

De toute façon ceci n'est pas de la poésie

Et si ce n'était que de la poésie

On aurait passé la plume à gauche

Depuis la découverte du nucléaire. 


\section{AUTEUR}

HAMIDOU VALIAN

Journaliste et auteur, Ouagadougou (Burkina Faso) 